\title{
Assessing the impact of a short-term service-learning clinical experience on the development of professional behaviors of student physical therapists: A pilot study
}

\begin{abstract}
Jeannette R. Anderson ${ }^{1}$, Leslie F. Taylor ${ }^{1}$, and Julie E. Gahimer ${ }^{2}$
As with most health care provider education programs, physical therapy programs seek ways to develop professional behaviors of students. This study describes the integration of a one-week service-learning experience into an existing clinical internship. Quantitative and qualitative data were analyzed between groups of students who participated in the experience, expressed a desire to participate but were unable to, and those who did not wish to participate. Results suggest that engaging in, as well as the desire to engage in, a servicelearning project for under-served members of our community is associated with professional behavior development from students' and clinical preceptors' perspectives.
\end{abstract}

Keywords: clinical education, professional development, professional socialization, core values, physical therapy, reflection

\section{Introduction}

Academic faculty and clinical preceptors have expressed concerns about student health care providers' professional behaviors (Carey \& Ness, 2001; Jette \& Portney, 2003). The question for physical therapist and other health care educators revolves around identifying effective teaching/learning methods for the development and enhancement of these behaviors. The purpose of this study was to determine the impact of a service-learning (S-L) activity, which involved providing physical therapy services to an underserved population in a multidisciplinary and non-traditional environment, on the development of professional behaviors of students. We hypothesized that engaging in the S-L experience would positively impact the development of professional behaviors of student physical therapists.

\section{Review of Literature}

Professional behaviors. Multiple descriptions are available for professionalism or professional behavior and concerns about professional behaviors of medical and health profession students are common (Arnold, 2002; Hammer, 2006; Jette \& Portney, 2003). In her study of professionalism in physical therapy, Gleeson (2007) states it may include topics such as communication, loyalty, appropriate dress, and work habits. She further states that there may be differences in how professional behaviors are displayed across generations of physical therapists or students. Gersh (2006) reminds us that defining professionalism has been a difficult task for

\footnotetext{
${ }^{1}$ Department of Physical Therapy, Mercer University, 3001 Mercer University Drive, Atlanta, GA 30341, anderson_jr@mercer.edu and taylor_lf@mercer.edu

${ }^{2}$ Krannert School of Physical Therapy, University of Indianapolis, 1044 East Hanna Avenue, Indianapolis, IN 46227, igahimer@unidy.edu
} 
many disciplines, and that the recent focus in physical therapy has been on instilling these behaviors in our therapists and students. Professional behavior expectations for physical therapists can be found in the American Physical Therapy Association's (APTA) Code of Ethics. (APTA Code of Ethics, 2006). Definitions of the values and sample indicators of professionalism can be found in APTA's The Core Values document (APTA Professionalism, 2003). The seven values are 1) accountability, 2) altruism, 3) compassion/caring, 4) excellence, 5) integrity, 6) professional duty, and 7) social responsibility.

Hammer (2006) defines professional socialization as "the process by which students learn and adopt the values, attitudes, and practice behaviors of a profession" (page 3). Warren May and colleagues (1995) were leaders in identifying and measuring "generic abilities" of physical therapists. These abilities are "attributes, characteristics, or behaviors that are not explicitly part of a profession's core of knowledge and technical skills, but nevertheless are required for success in that profession" (page 3). The 10 abilities are 1) commitment to learning, 2) interpersonal skills, 3) communication skills, 4) effective use of time and resources, 5) use of constructive feedback, 6) professionalism, 7) responsibility, 8) commitment to learning, 9) problem solving, and 10) stress management. These abilities are modeled, versus taught, in academic curricula and are commonly reported as issues by preceptors.

Wolff-Burke (2005) reported that physical therapist preceptors, commonly referred to as clinical instructors within the physical therapy profession, expect students to demonstrate acceptance of responsibility for learning, professionalism, empathy, and appropriate communication skills. She also identified preceptors concerns about inappropriate behaviors by students in the clinic, such as demonstrating an attitude of disengagement or lack of interest, poor communication, and being unprofessional, and contends inappropriate behaviors in these areas might be termed "generic inabilities." In her study, eight out of 10 generic abilities were represented in the expected appropriate behaviors; problem solving and critical thinking were not identified. In addition, she found the Core Values of accountability, compassion and caring, and excellence were also expected by preceptors as appropriate behaviors.

Service-Learning. "Service learning is a structured teaching and learning experience that meets identified needs in the community with explicit learning objectives, preparation, and reflection" (Reynolds, 2009, page 3). Service learning can positively shape the students' understanding of their discipline as well as their knowledge about specific social issues with which they are involved. (Kahne \& Westheimer, 1995). Seifer (1998) identifies five differences between service-learning experiences for health professions students and traditional clinical education: (1) service and learning are equal goals for the experience, (2) reciprocal learning occurs between the provider and receiver of services, (3) there is emphasis on citizenship and social change, (4) it emphasizes reflective practice, and (5) community partners identify their own needs. Providing services in non-clinical environments has been reported to be more effective in addressing learning of non-skill related objectives (Bringle \& Hatcher, 1996; Seifer, 1998).

Providing direct care to underserved populations as a service activity is not novel (O’Toole, Kathuria, Mishta, \& Schubert, 2005). Reynolds (2005) contends that cognitive theories support the use of service-learning as an educational tool and further describes clinical education as "a form of cognitive apprenticeship" (page 45). In her study, service-learning was effective in achieving objectives that are often difficult to address in traditional clinical education environments such as those related to professional development, social responsibility, awareness of individual and cultural differences, and application of prevention and wellness principles. 
Reflection papers on a short-term service-learning experience demonstrated moderate to high reflections on professional behaviors (Reynolds, 2005).

\section{Methods}

Subjects. All second-year Doctor of Physical Therapy (DPT) students (N=35) at a university in Georgia were offered the opportunity to participate in a one-week S-L experience involving students and faculty from several health professions programs (nurse practitioner, nursing, pharmacy, physical therapy, and dental hygiene) across the state, working together in a non-traditional environment to provide health care services to itinerate farm workers and their families. The DPT students were informed that they would provide developmental screens at an elementary school for the farmworkers' children, and examination, evaluation, and intervention of primarily musculoskeletal problems for the adults at their "camps" upon their return from the day's work.

Students were asked to indicate whether or not they had a general interest in participating in this type of activity. More students expressed interested in participating in the experience than could be accommodated. Students who wanted to be considered wrote a short explanation of reasons for desiring to participate, how this experience fit into their long-term goals, and any special skills they brought to the activity. Seven students were selected based on multiple subjective factors including involvement in preparation leading up to the activity (such as collecting donations of clothing and toys), faculty members' desires to provide new opportunities for students, students who had Spanish language skills, and if their clinical setting could logistically be truncated into seven weeks from eight.

Three groups of students were now potential participants for inclusion in the study. One group indicated interest and participated (S-L group; $n=7$ ), another group indicated interest but did not participate (INT group; $\mathrm{n}=12$ ), and the final group did not indicate interest nor participate (N-INT group; $n=16$ ). The INT group was specifically identified in the study because the S-L activity was voluntary; willingness and desire to volunteer for such an activity was thought to possibly impact the findings. Therefore, for further analysis of the impact of the desire to participate in the S-L activity, a combined group (Combo) of the S-L and the INT groups was compared to the N-INT group.

Study Design. Approval to conduct the research was received from the physical therapy program's institutional IRB and the first author's institution of doctoral study. All members of the class $(\mathrm{N}=35)$ were invited to participate and all provided consent. This was a mixed-design, prospective study; the actual research question and tools for measurement were determined, based on the literature, prior to initiating the study. The service-learning activity and the clinical internship occurred independent of this study. Students who did not participate in the servicelearning activity attended their assigned eight-week clinical internship. Students participating in the service-learning activity substituted the first week of their traditional eight-week clinical internship for the service-learning experience.

Instrumentation. Due to the subjectivity of measuring professionalism, several sources of assessment were used (Arnold, 2002; Parker, 2006). Quantitative data included two survey instruments, the Generic Ability Assessment (GAA) (May et al., 1995) and the Physical Therapist Clinical Performance Instrument for Students: Version 2006 (PT CPI) (Roach, Frost, Francis, Giles, Nordrum, \& Delitto, 2012). Students and preceptors completed the surveys at midway (week 4) and at the end of the clinical experience (week 8). Qualitative data included a 
student written reflection on communication/interpersonal skills at midterm and another on the Core Values at the end of the clinical experience. The outcome tools used midway and at the end of the clinical internship are shown in Table 1.

The GAA provides a three-point ordinal scale (beginning, developing, and entry-level) for assessment of ten behaviors associated with success in the profession (May et al., 1995). Instructions guided both the student and preceptors to circle the level most represented by the student's performance. The PT CPI allows self-assessment and preceptor assessment of a student physical therapist's abilities on 18 performance criteria. The performance criteria are grouped into the following 3 categories: "professional practice," "patient management," and "practice management." The professional practice criteria include specific performance assessments for six criteria, including safety, professional behavior, accountability, communication, cultural competence, and professional development (Roach et al., 2012). A rating scale of six defined anchors (beginning, advanced beginning, intermediate, advanced intermediate, entry-level, and beyond entry-level) require(d) meeting a specified achievement. For the purpose of this study, the professional practice category was included as the criteria within this category are similar to the generic abilities.

Two reflections (one at the midpoint and one at the end of the internship) were private exchanges via email from the students to the primary author, who served as the program's academic coordinator of clinical education (ACCE). The first reflection topic came directly from Plack's (2006) efforts to determine how student physical therapists learn communication and interpersonal skills. Students in her study and this study were asked to:

"Think back, and provide a detailed description of an experience which helped you better understand and ultimately develop the communication and interpersonal skills essential to being a physical therapist. This incident can be either positive or negative and should be particularly meaningful to you as an individual" (page 39).

The second reflection topic was related to the APTA's Core Values:

"Review APTA's Core Values (including definitions and sample indicators). Think back on the entire 8 weeks of Clinical Internship III. Describe a situation that has most impacted you as a future physical therapist in relationship to one of the Core Values. Clearly identify the Core Value, provide a detailed description of the situation and how it has shaped you as a future physical therapist."

Data Collection and Quantitative Coding Procedures. Materials for this study were collected as part of the established process of the course. Data were key coded and identifying information removed for the purpose of analysis. Analysis occurred after grades were posted.

Data Analysis. Quantitative data were analyzed using the statistical software package SPSS Version 17 (SPSS, 2008). Kruskal-Wallis tests were performed and descriptive statistics were computed on the three groups' ordinal data; an alpha level of 0.05 was set. The MannWhitney U tests were used to analyze specific sample pairs for significant differences. Data from combining the S-L and INT group to compare to the N-INT group were analyzed by MannWhitney $\mathrm{U}$ tests with an alpha level set at 0.05 .

The qualitative data (midterm reflections) were analyzed using a grounded theory approach and assessed to determine themes and subthemes from the data with subsequent coding of each reflection (Hesse-Bieber \& Leavy, 2006). Two reviewers independently read the reflections and developed a draft coding framework from the data. Two subsequent meetings lead to identification of major themes and subcategories within the midterm reflection data. Reviewers then read the data again, coded the data, and compared and discussed until consensus 
was reached. Final reflections were assessed for the specific clinical situation and Core Value identified by the student.

Table 1

Outcome Tools

\begin{tabular}{|c|c|c|c|}
\hline Outcome Tool & Quantitative Data & $\begin{array}{l}\text { Variables or } \\
\text { Constructs }\end{array}$ & Qualitative Data \\
\hline $\begin{array}{l}\text { Generic Ability } \\
\text { Assessment (GAA) } \\
\text { Completed by student } \\
\text { and preceptor at end of } \\
\text { week } 4 \text { and week } 8\end{array}$ & $\begin{array}{l}3 \text { point ordinal scale } \\
1=\text { Beginning } \\
2=\text { Developing } 3=\text { Entry- } \\
\text { level }\end{array}$ & $\begin{array}{l}\text { 1.Commitment to } \\
\text { learning } \\
\text { 2. Interpersonal skills } \\
\text { 3. Communication } \\
\text { 4. Use of constructive } \\
\text { feedback } \\
\text { 5. Effective use of } \\
\text { time or resources } \\
\text { 6. Problem solving } \\
\text { 7. Professionalism } \\
\text { 8. Responsibility } \\
\text { 9. Critical thinking } \\
\text { 10. Stress } \\
\text { management }\end{array}$ & \\
\hline $\begin{array}{l}\text { The Professional } \\
\text { Practice Criteria of the } \\
\text { Physical Therapist } \\
\text { Clinical Performance } \\
\text { Instrument for Students } \\
\text { (PT CPI) } \\
\text { Completed by student } \\
\text { and preceptor at end of } \\
\text { week } 4 \text { and week } 8\end{array}$ & $\begin{array}{l}10 \text { point ordinal scale via } \\
\text { radio bullets with } \\
\text { defined anchors. } \\
0=\text { beginning } \\
2=\text { adv. beginning } \\
4=\text { intermediate } \\
6=\text { adv. intermediate } \\
8=\text { entry-level } \\
10=\text { beyond entry-level }\end{array}$ & $\begin{array}{ll}\text { 1. } & \text { Safety } \\
\text { 2. } & \text { Professional } \\
& \text { Behavior } \\
\text { 3. } & \text { Accountability } \\
\text { 4. } & \text { Cultural } \\
\text { 5. } & \text { Competence } \\
\text { 5. } & \text { Communication } \\
\text { 6. } & \text { Professional } \\
& \text { Development }\end{array}$ & \\
\hline $\begin{array}{l}\text { Student Reflections } \\
\text { Completed by student at } \\
\text { week } 4 \text { (midpoint) and } \\
\text { week } 8 \text { (final) }\end{array}$ & & & $\begin{array}{l}\text { Midpoint: an experience } \\
\text { which helped you better } \\
\text { understand and } \\
\text { ultimately develop the } \\
\text { communication and } \\
\text { interpersonal skills } \\
\text { essential to being a } \\
\text { physical therapist Final: } \\
\text { a situation that has most } \\
\text { impacted you as a future } \\
\text { physical therapist in } \\
\text { relationship to one of } \\
\text { the Core Values }\end{array}$ \\
\hline
\end{tabular}

Journal of the Scholarship of Teaching and Learning, Vol. 14, No. 4, October 2014. 


\section{Results}

Quantitative. Mean scores from the GAA from students and preceptors at midterm and final are displayed on Table 2. Assessment of students' scores on the ten categories of the GAA, and a total summed score revealed one difference. Self-assessments of Interpersonal Skills at the end of the eight-week clinical experience were different $(\mathrm{p}=.018)$ between the 3 groups, with the N-INT group scoring the lowest with a mean of 2.25. There was no difference between the S-L and INT groups (means were 2.71 and 2.75 , respectively). Further assessment of the combined group (2.74) to the N-INT group (2.25), demonstrated that the difference remained ( $\mathrm{p}=.005)$.

Assessment of preceptor's ratings on the GAA identified other differences. Midway through the clinical experience, Effective Use of Time and Resources differed between the three groups ( $\mathrm{p}=.031$ ), with the N-INT group scoring lowest (1.81). Again, there was no difference between the S-L and INT groups whose means were 2.14 and 2.25, respectively. The S-L and INT groups were collapsed for additional analysis $(\mathrm{p}=.010)$. At the final assessment (week 8), additional differences were identified between the two groups, including lower scores given to the N-INT group for Commitment to Learning $(p=.019)$ and Critical Thinking $(p=.031)$. Summed final scores of the GAA revealed differences between the 2 groups for student $(\mathrm{p}=.040)$ and preceptor $(\mathrm{p}=.036)$ assessment, where, again, the N-INT scored lower. The preceptors also provided five instances of mean scores of 3, the highest possible, to the S-L group for Commitment to Learning, Interpersonal Skills, Constructive Feedback, Professionalism, and Responsibility. Neither the INT or N-INT group received this optimal score.

The CPI data demonstrated no differences between the groups for mid-point or final scores on the constructs of Professional Practice. All students were scored at the intermediate level (minimum score of 4) at the conclusion of the eight week clinical internship via self and preceptor assessment. 
Table 2

Mean Scores from the Generic Abilities Assessment

\begin{tabular}{|c|c|c|c|c|c|c|c|c|c|c|c|c|c|c|c|c|}
\hline & \multicolumn{4}{|c|}{ Student Midterm } & \multicolumn{4}{|c|}{ Student Final } & \multicolumn{4}{|c|}{ Preceptor Midterm } & \multicolumn{4}{|c|}{ Preceptor Final } \\
\hline & $\mathrm{S}-\mathrm{L}$ & INT & $\begin{array}{c}\mathrm{N}- \\
\mathrm{INT}\end{array}$ & Comb & S-L & INT & $\begin{array}{c}\mathrm{N}- \\
\mathrm{INT}\end{array}$ & Comb & S-L & INT & $\begin{array}{c}\mathrm{N}- \\
\mathrm{INT}\end{array}$ & Comb & S-L & INT & $\begin{array}{c}\mathrm{N}- \\
\mathrm{INT}\end{array}$ & Comb \\
\hline $\begin{array}{l}\text { Commitment to } \\
\text { Learning }\end{array}$ & 2.14 & 2.50 & 2.19 & 2.37 & 2.57 & 2.75 & 2.44 & 2.68 & 2.29 & 2.75 & 2.38 & 2.58 & 3.00 & 2.91 & 2.63 & $2.95^{*}$ \\
\hline $\begin{array}{l}\text { Interpersonal } \\
\text { Skills }\end{array}$ & 2.29 & 2.33 & 2.06 & 2.32 & 2.71 & 2.75 & $\begin{array}{l}2.25 * \\
2.25 \\
\end{array}$ & $2.74 * *$ & 2.43 & 2.50 & 2.25 & 2.47 & 3.00 & 2.83 & 2.63 & 2.89 \\
\hline Communication & 2.14 & 2.17 & 2.00 & 2.15 & 2.57 & 2.33 & 2.31 & 2.42 & 2.14 & 2.33 & 2.31 & 2.26 & 2.85 & 2.67 & 2.63 & 2.74 \\
\hline $\begin{array}{l}\text { Effective Use } \\
\text { Time/Resources }\end{array}$ & 2.00 & 2.00 & 2.00 & 2.00 & 2.42 & 2.50 & 2.19 & 2.47 & 2.14 & 2.25 & $\begin{array}{c}1.81 * \\
1.81 \\
\end{array}$ & $2.21 * *$ & 2.57 & 2.75 & 2.50 & 2.68 \\
\hline $\begin{array}{l}\text { Use } \\
\text { Constructive } \\
\text { Feedback }\end{array}$ & 2.14 & 2.17 & 2.19 & 2.16 & 2.71 & 2.41 & 2.38 & 2.53 & 2.57 & 2.58 & 2.44 & 2.58 & 3.00 & 2.83 & 2.63 & 2.89 \\
\hline $\begin{array}{l}\text { Problem } \\
\text { Solving }\end{array}$ & 2.00 & 2.17 & 2.00 & 2.11 & 2.14 & 2.33 & 2.19 & 2.26 & 2.00 & 2.00 & 1.88 & 2.00 & 2.43 & 2.50 & 2.25 & 2.47 \\
\hline Professionalism & 2.29 & 2.58 & 2.62 & 2.47 & 3.00 & 2.83 & 2.75 & 2.89 & 2.57 & 2.75 & 2.63 & 2.69 & 3.00 & 2.91 & 2.81 & 2.95 \\
\hline Responsibility & 2.42 & 2.33 & 2.13 & 2.37 & 2.57 & 2.58 & 2.31 & 2.58 & 2.42 & 2.50 & 2.31 & 2.47 & 3.00 & 2.75 & 2.62 & 2.84 \\
\hline $\begin{array}{l}\text { Critical } \\
\text { Thinking }\end{array}$ & 2.14 & 2.00 & 2.06 & 2.05 & 2.14 & 2.17 & 2.19 & 2.16 & 2.14 & 2.17 & 2.00 & 2.16 & 2.71 & 2.67 & 2.31 & $2.68 *$ \\
\hline $\begin{array}{l}\text { Stress } \\
\text { Management }\end{array}$ & 2.29 & 2.58 & 2.50 & 2.47 & 2.43 & 2.83 & 2.69 & 2.68 & 2.14 & 2.67 & 2.43 & 2.47 & 2.57 & 2.91 & 2.69 & 2.79 \\
\hline Total Score & 21.86 & 22.83 & 21.75 & 22.47 & 25.29 & 25.50 & 23.50 & $25.42 *$ & 22.86 & 24.50 & 22.43 & 23.89 & 28.14 & 27.75 & 25.69 & $27.89 *$ \\
\hline
\end{tabular}

$* \mathrm{p}<.05, * * \mathrm{p}<.01$ 
Qualitative. Midterm Reflections. Four main themes (refer to table 3) emerged from the midterm student reflection papers on an experience that helped them understand and develop communication/interpersonal skills essential for being a physical therapist: 1) establishing a therapeutic relationship, 2) the importance of educating patients, 3) assertive communication situations, and 4) student introspection.

Table 3

Midterm Reflection Themes and Subcategories

\begin{tabular}{|c|c|c|}
\hline Main Themes & General Definition & Subcategories \\
\hline \multirow[t]{3}{*}{ Therapeutic Relationship } & \multirow[t]{3}{*}{$\begin{array}{l}\text { Identifies } \\
\text { situations related } \\
\text { to establishing a } \\
\text { therapeutic } \\
\text { relationship }\end{array}$} & $\begin{array}{l}\text { Patient is center, but therapist controls situation: } \\
\text {-reaching patient } \\
\text {-connection } \\
\text {-gaining trust } \\
\text {-establishing rapport } \\
\text {-allowing patient to say their piece } \\
\text {-active listening } \\
\text {-affirm/validate }\end{array}$ \\
\hline & & $\begin{array}{l}\text { Dealing with patient emotions or demonstrating } \\
\text { compassion/caring/empathy }\end{array}$ \\
\hline & & Non-verbal behaviors \\
\hline \multirow[t]{2}{*}{ Education } & \multirow{2}{*}{$\begin{array}{l}\text { Identifies } \\
\text { situations related } \\
\text { to the importance } \\
\text { of education }\end{array}$} & $\begin{array}{l}\text { Strategies of teaching and patient learning for: } \\
\text {-understanding } \\
\text {-adherence }\end{array}$ \\
\hline & & Effectiveness of teaching treatment \\
\hline \multirow{4}{*}{$\begin{array}{l}\text { Assertive } \\
\text { Communication }\end{array}$} & \multirow{4}{*}{$\begin{array}{l}\text { Identifies } \\
\text { situations related } \\
\text { to assertive } \\
\text { communication }\end{array}$} & $\begin{array}{l}\text { Confidence/assertiveness related to } \\
\text { education/treatment }\end{array}$ \\
\hline & & Defending self and/or profession to others \\
\hline & & Lack of assertive communication \\
\hline & & Difficulty of assertive communication \\
\hline \multirow[b]{2}{*}{$\begin{array}{l}\text { Student } \\
\text { Introspection }\end{array}$} & \multirow{2}{*}{$\begin{array}{l}\text { Demonstrates } \\
\text { introspection of } \\
\text { student's } \\
\text { role }\end{array}$} & Regarding feeling positive for future success \\
\hline & & Regarding their need for change/development \\
\hline
\end{tabular}

The students in the S-L group described experiences in which establishing a therapeutic relationship was the most important for their understanding and developing the communication and interpersonal skills essential to being a physical therapist. Establishing a therapeutic relationship was described twice as often for this group as the next most commonly described experiences, which related to introspection. None of these students identified experiences that occurred during the S-L activity as the ultimate in shaping their communication and interpersonal skills. In contrast, students in the INT group described experiences related to assertive communication. Introspection on their own performance occurred similar to that of the $\mathrm{S}-\mathrm{L}$ group. More than half of their reflections included therapeutic relationship themes. The students in the N-INT group had the fewest examples of introspection on their communication and interpersonal skills; rather, the emphasis was on education and focused more on technical and/or procedural aspects of improving patient/client experiences and outcomes. 
Qualitative. Final Reflections. Refer to the Appendix for examples of student reflections, and to Table 4 for the percentage of students identifying a specific core value as related to a situation that had the most impact on their development as a future physical therapist. As noted in the research by Wolff-Burke (2005), the students in the INT and N-INT groups indentified situations related to the core value of Compassion and Caring most often. Ten of 11 students in the INT group identified situations that related to Compassion and Caring and over two-thirds of the students in the N-INT group identified situations related to Compassion and Caring. Of the 7 students in the S-L group, over half described a situation related to Altruism that most impacted them as a future physical therapist. Nearly three-quarters of those students specifically mentioned the S-L activity as the one experience that impacted them the most. One student's response in the INT group was not considered in the analysis as the reflection included examples of how all the core values were demonstrated and influential.

Table 4

APTA Core Value Identification of Final Reflections

\begin{tabular}{|l|l|l|l|}
\hline $\begin{array}{l}\text { Percentage of Students Who Identified Specific } \\
\text { Core Value as Most Influential }\end{array}$ & S-L group & INT group & N-INT group \\
\hline & & $8 \%$ & \\
\hline Accountability & $57 \%$ & & $25 \%$ \\
\hline Altruism & $29 \%$ & $83 \%$ & $69 \%$ \\
\hline Compassion/Caring & & & \\
\hline Excellence & & & $6 \%$ \\
\hline Integrity & & & \\
\hline Professional Duty & $14 \%$ & & \\
\hline Social Responsibility & & & \\
\hline
\end{tabular}

*One student's reflection removed from consideration as all values mentioned as influential.

\section{Discussion and Conclusion}

This study considered the impact of including a one-week service-learning clinical experience in a non-traditional setting, as an adjunct to the traditional clinical internship, on the development of professional behaviors of doctor of physical therapy students. During the traditional clinical internship, students who participated in the S-L activity, those who were interested, and those who were not interested, all demonstrated the expected and required levels of professional behaviors for success in the course. Students who replaced one week of the traditional internship with this S-L activity, or who simply desired the opportunity to participate, rated their own professional behaviors at a higher level than those who were not interested in the activity. This was also supported by preceptor ratings of the students' professional behaviors.

Reflection may be the key to understanding why the S-L and INT groups had higher selfassessment and preceptor ratings on the GAA. Cruess and Cruess (2006) state that opportunities for self-reflection allow for internalization of values. They further support providing students a variety of experiences and role modeling opportunities. Certainly this service-learning activity was unique to what other students experienced; further, role modeling of altruism by multidisciplinary faculty members was apparent. 
Clinical preceptors' higher ratings of the S-L students' professional behaviors on the GAA in this pilot study is consistent with the previously reported data on the effectiveness of service-learning on the development of professional behaviors (Reynolds, 2005). The definition of Commitment to Learning includes "the ability to self-assess, self-correct, and self-direct" which would require the ability to reflect. The S-L group had the highest possible ratings of this ability from clinical preceptors (a mean rating of 3 out of 3). This was also consistent with the higher percentages of student introspection in the mid-term written statements for the S-L and INT groups.

There is debate in the literature about whether Critical Thinking is a sign of professional behavior. While preceptors in Wolff-Burke's (2008) study did not identify Critical Thinking as a professional behavior, CIs and students in May and colleagues (1995) and Jette and Portney's (2003) studies support the inclusion of this trait as part of professionalism. The combined group in our study received higher final scores by their preceptors of this behavior. Students who participated in the S-L experience were exposed to difficult clinical cases and limited availability of intervention options; critical thinking should have been challenged by the service-learning experience. This appears to have transferred over to, or been reinforced in, their performance in the traditional clinical environment. Further, the definition of this skill includes "the ability to question logically" which would require reflection on the problem at hand.

Midterm reflections revealed a difference in the types of experiences the three groups of students perceived as most valuable to developing their communication and interpersonal skills. Students in the S-L group recalled experiences related to establishing a therapeutic relationship. Students in the INT group most often reported situations that dealt with their feelings about the challenges or successes interacting with others in an assertive manner. These reflections corroborate both groups' higher ratings on the interpersonal skills category of the GAA. There are many similarities to the GAA descriptors for interpersonal skills and the reflections. For the S-L group, this relates to Johnson and colleagues (2006) findings that student reflections on their interpersonal communication improved after working in pro bono clinics.

Further, overall reflection on performance was most common for the students in the S-L group, which is consistent with the findings on the self-assessment and preceptors' assessment of student performance on the CPI. Plack (2006) believes that dialogue creates shared meaning and subsequent professional identity. During participation in the service-learning activity, the students engaged in daily interdisciplinary reflection. Reflections from the S-L group on their own performance were similar to those interested in participation (INT group) but more prevalent than those who were not interested in participating.

Research supports S-L in non-clinical settings for health professions students, so as to avoid emphasis on profession-specific cognitive and psychomotor skills (Bringle \& Hatcher, 1996; Seifer, 1998). This experience occurred in a unique clinical environment in a nontraditional setting with an underserved population. Replacing one-week of the students' 8-week clinical time appeared to be influential in regard to developing professionalism as defined by the physical therapy profession's core values. This experience was clearly service-learning as students learned about the living and working environments of the patients/clients, their health disparities and available health care resources, and roles of other health care professionals. In particular, the values of Altruism and Social Responsibility were evident in their reflections, and were not identified by the other students. Reynolds (2009) states that volunteerism and community service "arouse a powerful sense of altruism that can be easily expressed (page 4)." 
Limitations. The DPT students who participated in the S-L activity were chosen by 2 faculty members, one of whom was the Academic Coordinator of Clinical Education (ACCE) and the primary author of this paper. The other faculty member had no interaction or participation in this study. The selection criteria could have been biased toward those students who might already be more sensitized to community service. However, it also important to remember that the feasibility of their clinical internship was equally, or more, significant in the selection process. All 35 students were eligible to go; no student was in academic jeopardy. The addition of comparing two groups (those who attended or were interested in attending to those who did not wish to participate) strengthens the validity of the analysis. Certainly the sample size is of concern; however, it was one of convenience based on a clinical and academic reality, and was appropriate to the question. This study is investigatory; triangulation of data was performed to strengthen the validity of the findings.

Future Research. Health professions programs must not only train future practitioners in clinical skills, but also in professional behaviors. Participation in service-learning appears to develop both clinical skills and professional behaviors while also playing an important role within the community. Further studies, with larger groups of students in a variety of health care programs would add to the validity of the findings of this study. An unexpected finding is that it appears there is a positive relationship between students' perceived professional behaviors and just having a desire to participate in S-L activities. Continued research into whether these behaviors are inherent or whether they are learned or nurtured by participating in the actual activity may be the most appropriate question. Application of outcomes could assist in interviewing students for traits that could be helpful in determining future clinical success. Integration of service-learning pedagogy into the curricula of healthcare programs may benefit the practitioner and ultimately those individuals with whom we are privileged to serve.

\section{Acknowledgements}

The authors would like to acknowledge Stephanie P. Kelly, PT, PhD for her role as a member of the first author's juried project committee.

\section{Appendix}

\section{Appendix 1: Examples of Qualitative Data}

S-L \#3: "I could feel his depression just sitting in the air. ... I made sure to make him as comfortable as possible and try to put him at ease. I asked open ended questions until he was talking a little more freely. I used all of the skills we learned in psychosocial class to affirm and validate what he was telling me. ... I tried to communicate verbally and nonverbally with my body language that I sympathized with his situation. ... I made sure to let him know that he was always in charge, ..." (Therapeutic Relationship)

INT \#14: "I was obviously upset. I had let my feeling of being inferior as a student to a professional get in the way of making what I knew to be the right decision. ...it was a learning experience for me to have enough confidence in myself to speak out when I think something is wrong. At the end of the experience this may be the biggest lesson that I will have learned." (Assertive Communication) 
N-INT \#15: "Now came the hard part, trying to explain to the patient what was going on in her body. I started off trying to explain... she may have stretched the nerves.... I could tell by the blank stare that was giving me that she really did not understand what or how what I was telling her could be causing her symptoms. I brought over the model of the spine, ... She started to understand a little more,... I then took her over to the poster we have of the nervous system... Now I had to explain why her body was not allowing her to move her arms in certain directions, and how I was going to help her. This process took a lot of time, but at the end she understood this and it started to make sense to her. I ended up spending a lot more time educating the patient her first session than I expected..." (Importance of Education)

S-L \#3: "XXX is exactly what altruism describes. ... We were able to put those patients' needs above our own. As physical therapist we usually need things like, bright light so we can see, air conditioning mostly for comfort, no bugs also for comfort, and sensible working hours. In XXX that was not going to happen. We wanted to help these people so that's what we had to put up with; little light, heat, bugs, and late long hours. ...Last year when I had to write about altruism I couldn't imagine how PTs would do pro-bono work and now I have a fantastic example of it. " (Altruism)

INT \#14: "I believe I was successful in the acute care setting because my compassion and caring was evident to each of my patients. ...After meeting her for the first time, I had a good read of what she liked, and would bring her a hot cup of coffee to wake her up and motivate her consent to treatment. During our walk, I listened as she talked about her children and her life as a young girl. ... Each day before I left her room, she would say, 'I have just one more thing to say. Thank you for being you. I love that smile you have, it always makes me feel so good. You know that not everyone treats an old woman the way that you do, allowing me to make my own decisions and not commanding me to do things." (Compassion/ Caring)

\section{References}

American Physical Therapy Association. (2003). Professionalism in physical therapy: Core values. Retrieved October 31, 2009 from http://www.apta.org/documents/public/education/professionalism.pdf)

American Physical Therapy Association (APTA). (2006). Code of Ethics. Retrieved October 30, 2009 from http://www.apta.org/uploadedFiles/APTAorg/About_US/Policies/HOD/Ethics/Codeofethics.pdf.

Arnold, L. (2002). Assessing professional behavior: Yesterday, today, and tomorrow. Academic Medicine, 77(6), 502-515. doi: 10.1097/00001888-200206000-00006

Bringle, R., \& Hatcher, J. (1996). Implementing service learning in higher education. Journal of Higher Education, 67(2), 221-238. doi: 10.2307/2943981 
Carey, J., \& Ness, K. (2001). Erosion of professional behaviors in physical therapist students. Journal of Physical Therapy Education, 15, 20-22.

Cruess, R., \& Cruess, S. (2006). Teaching professionalism: General principles. Medical Teacher, 28(3), 205-208. doi: 10.1080/01421590600643653

Gersh, M. (2006). Servant-leadership: A philosophical foundation for professionalism in physical therapy. Journal of Physical Therapy Education, 20, 12-16.

Gleeson, P. (2007). Understanding generational competence related to professionalism: misunderstandings that lead to perception of unprofessional behavior. Journal of Physical Therapy Education, 21, 23-28.

Hammer, D. (2006). Improving student professionalism during experiential learning. American Journal of Pharmaceutical Education, 70(3) Article 59, 1-6.

Hesse-Biber, S. H., \& Leavy, P. (2006). The Practice of Qualitative Research. Thousand Oaks, CA: Sage Publications, Inc.

Jette, D., \& Portney, L. (2003). Construct validation of a model for professional behavior in physical therapist students. Physical Therapy, 83, 432-443.

Johnson, M., Maritz, C., \& Lefever, G. (2006). The Mercy Circle of Care: An interdisciplinary, multi-institutional collaboration to promote community health and professional education. Journal of Physical Therapy Education, 20, 73-79.

Kahne, J., \& Westheimer, J. (1996). In service of what? The politics of service learning. Phi Delta Kappan. 77, 593-599.

May, W., Morgan, B., Lemke, J., Karst, G., \& Stone, H. (1995). Model for ability-based assessment in physical therapy education. Journal of Physical Therapy Education, 9(1), 3-6.

Seifer, S. (1998). Service-learning: Community-campus partnerships for health professions education. Academic Medicine, 73, 273-277. doi: 10.1097/00001888-199803000-00015

O'Toole, T., Kathuria, N., Mishra, M., \& Schukart, D. (2005). Teaching professionalism within a community context: Perspectives from a national demonstration project. Academic Medicine, 80(4), 339-343. doi: 10.1097/00001888-200504000-00006

Parker, M. (2006). Assessing professionalism: Theory and practice. Medical Teacher, 28, 399403. doi: 10.1080/01421590600625619

Plack, M. (2006). The development of communication skills, interpersonal skills, and a professional identity within a community of practice. Journal Of Physical Therapy Education, 20(1), 37-46. 
Reynolds, P. (2005). How service-learning experiences benefit physical therapist students' professional development: A grounded theory study. Journal of Physical Therapy Education, 19(1), 41-54.

Reynolds, P. (2009). Community engagement: What's the difference between service-learning, community service, and community-based research? Journal of Physical Therapy Education, 23(2), 3-9.

Roach, K., Frost, J., Francis, N., Giles, S., Nordrum, J., \& Delitto, A. (2012). Validation of the Revised Physical Therapist Clinical Performance Instrument (PT CPI): Version 2006. Physical Therapy, 92, 416-428. doi: 10.2522/ptj.20110129

SPSS Inc. Released 2008. SPSS Statistics for Windows, Version 17.0. Chicago: SPSS Inc. Wolff-Burke, M. (2005). Clinical instructors' descriptions of physical therapist student professional behaviors. Journal of Physical Therapy Education, 19, 67-76. 